\title{
Controlling self-assembling and tumor cell-targeting of protein-only nanoparticles through modular protein engineering
}

\author{
Eric Voltà-Durán ${ }^{1,2,3}$, Olivia Cano-Garrido ${ }^{1,4}$, Naroa Serna ${ }^{1,2,3}$, Hèctor López-Laguna ${ }^{1,2,3}$, \\ Laura Sánchez-García ${ }^{1,2,3}$, Mireia Pesarrodona ${ }^{1,2,3 \#}$, Alejandro Sánchez-Chardi ${ }^{6}$, Ramón Mangues ${ }^{3,5}$, \\ Antonio Villaverde ${ }^{1,2,3^{*}}$, Esther Vázquez ${ }^{1,2,3^{*}}$ and Ugutz Unzueta ${ }^{3,5}$
}

\begin{abstract}
Modular protein engineering is suited to recruit complex and multiple functionalities in single-chain polypeptides. Although still unexplored in a systematic way, it is anticipated that the positioning of functional domains would impact and refine these activities, including the ability to organize as supramolecular entities and to generate multifunctional protein materials. To explore this concept, we have repositioned functional segments in the modular protein T22GFP-H6 and characterized the resulting alternative fusions. In T22-GFP-H6, the combination of T22 and $\mathrm{H} 6$ promotes selfassembling as regular nanoparticles and selective binding and internalization of this material in CXCR4-overexpressing tumor cells, making them appealing as vehicles for selective drug delivery. The results show that the pleiotropic activities are dramatically affected in module-swapped constructs, proving the need of a carboxy terminal positioning of $\mathrm{H} 6$ for protein self-assembling, and the accommodation of T22 at the amino terminus as a requisite for $\mathrm{CXCR4}^{+}$cell binding and internalization. Furthermore, the failure of self-assembling as regular oligomers reduces cellular penetrability of the fusions while keeping the specificity of the T22-CXCR4 interaction. All these data instruct how multifunctional nanoscale protein carriers can be designed for smart, protein-driven drug delivery, not only for the treatment of $\mathrm{CXCR}^{+}$human neoplasias, but also for the development of anti-HIV drugs and other pathologies in which CXCR4 is a relevant homing marker.
\end{abstract}

Keywords: nanoparticles, protein materials, recombinant proteins, drug delivery, self-assembling, cancer cell targeting

\section{INTRODUCTION}

Protein-based drug delivery offers promises in the design of innovative drug delivery systems, especially when intended for precision medicines that require selective penetration of the therapeutic agent into target cells [1]. Proteins and peptides, over other materials commonly explored as drug delivery systems, offer high structural and functional versatility easily regulatable by genetic engineering. This flexibility allows generating protein materials non-existing in nature, with novel functions or combinations of them, for appealing applications [2-8].

Among different strategies of protein engineering, modular genetic fusion permits the recruitment, in single polypeptide chains, of multiple biological activities [9], and their simple biological production in recombinant forms [10]. Such modular concept has been widely used in cancer therapies [11-13], where the combination of targeting and cytotoxic domains is a common issue [10,14-18]. Usually, the precise order of modular placement in multifunctional proteins is based on trial-anderror assisted by the background about protein functionalities when amino or carboxy termini are blocked, as

\footnotetext{
${ }^{1}$ Institut de Biotecnologia i de Biomedicina, Universitat Autònoma de Barcelona, Bellaterra, 08193 Barcelona, Spain

${ }^{2}$ Departament de Genètica i de Microbiologia, Universitat Autònoma de Barcelona, Bellaterra, 08193 Barcelona, Spain

${ }^{3}$ CIBER de Bioingeniería, Biomateriales y Nanomedicina (CIBER-BBN), C/Monforte de Lemos 3-5, 28029 Madrid, Spain

${ }^{4}$ Nanoligent SL, Edifici EUREKA, Universitat Autònoma de Barcelona, Bellaterra, 08193 Barcelona, Spain

${ }^{5}$ Institut d'Investigacions Biomèdiques Sant Pau and Josep Carreras Research Institute, Hospital de la Santa Creu i Sant Pau, 08041 Barcelona, Spain

${ }^{6}$ Departament de Biologia Evolutiva, Ecologia i Ciències Ambientals, Facultat de Biologia, Universitat de Barcelona, Av. Diagonal 643, 08028 Barcelona, Spain

\# Present address: Institute for Research in Biomedicine (IRB Barcelona), The Barcelona Institute of Science and Technology, 08028 Barcelona, Spain *Corresponding authors (emails: antoni.villaverde@uab.cat (Villaverde A); Esther.Vazquez@uab.cat (Vázquez E))
} 
clinically relevant peptides might require free ends for biological functions. Examples of full structure-based rational design, although existing, are not abundant [9,19-22]. Recently, we have adapted the modular protein T22-GFP-H6 as a self-assembling protein-based tumortargeted vehicle for pro-apoptotic factors [18] and for the antitumoral drug floxuridine [23]. The use of this vehicle for precision cancer medicine has resulted in reduced tumor volume, but specially in less metastatic foci in mouse models of colorectal cancer [23]. T22-GFP-H6 is produced in recombinant bacteria and oligomerizes into toroid nanoparticles of $12 \mathrm{~nm}$ [24], representing a paradigmatic example of universal transversal self-assembling protein platform based on a combination of cationic peptides and polyhistidines [25]. Self-assembling of T22GFP-H6 requires the cationic peptide T22, a polyphemusin II-derivative [26] that acts as a potent ligand $[27,28]$ of the tumoral marker CXCR4 [29]. Self-organization of the protein also requires a histidine rich-region (H6) responsible for divalent cation-mediated proteinprotein interactions [30]. The optimal position of these functional modules has not been previously assessed, as it derives from early data describing the architectonic potential of cationic peptides in GFP fusions [31]. Since CXCR4 is overexpressed in more than 20 human neoplasias [32-37], developing optimal protein vehicles as CXCR4-selective drug carriers would be highly desirable. On the other hand, the use of histidine-rich regions as protein connectors is of obvious interest for the construction of tailored protein materials.

In this context, we explored the potential impact of modular swapping in the model T22-GFP-H6, on those properties critical for its role as drug vehicle, including assembling capacity, selective CXCR4-targeting and cell internalization. Being the properties of T22-GFP-H6 extensible to the protein self-assembling platform irrespective of the involved functional domains, this information is of pivotal relevance for the further design of built-in, protein-only antitumoral drugs within the nanoscale for active tumor targeting $[13,14,38]$.

\section{METHODS}

\section{Genetic design, protein production and purification}

The nomenclature of the proteins has been established according to their modular organization. An Escherichia coli (E. coli) codon-optimized gene encoding H6-GFPT22 was designed in house and provided by Geneart (ThermoFisher) inserted in pET22b. Details of the other gene fusions can be found elsewhere [30] and the prop- erties of the encoded proteins are summarized in Fig. 1a. The plasmids were transformed in E. coli Origami B (BL21, OmpT ${ }^{-}$, Lon ${ }^{-}$, TrxB, Gor ; Novagen). All proteins were produced in bacterial cells cultured in Lysogenic Broth (LB) medium (supplemented with $100 \mu \mathrm{g} \mathrm{mL}^{-1}$ ampicillin, $12.5 \mu \mathrm{g} \mathrm{mL}^{-1}$ tetracycline and $15 \mu \mathrm{g} \mathrm{mL}^{-1}$ kanamycin) at $20^{\circ} \mathrm{C}$ overnight, upon induction with $0.1 \mathrm{mmol} \mathrm{L}^{-1}$ of isopropyl- $\beta$ - $D$-thiogalactopyronaside (IPTG). H6-GFP-T22 gene expression was triggered with $0.1 \mathrm{mmol} \mathrm{L}^{-1}$ IPTG during $3 \mathrm{~h}$ at $37^{\circ} \mathrm{C}$, for an optimal yield. Bacteria cells were then harvested by centrifugation $(15 \mathrm{~min}, 5000 \times \mathrm{g})$ and resuspended in wash buffer $\left(20 \mathrm{mmol} \mathrm{L}^{-1}\right.$ Tris- $\mathrm{HCl}, 500 \mathrm{mmol} \mathrm{L}^{-1} \mathrm{NaCl}, 10 \mathrm{mmol} \mathrm{L}^{-1}$ imidazole, $\mathrm{pH}$ 8) in presence of protease inhibitors (Complete EDTA-free, Roche Diagnostics), before being disrupted in a French Press (Thermo FA-078A) by two rounds at $1200 \mathrm{psi}$. Soluble fractions were collected as the supernatant after centrifugation for $45 \mathrm{~min}$ at $15,000 \times \mathrm{g}$.

Proteins were finally purified by immobilized metal affinity chromatography (IMAC) using HisTrap HP $1 \mathrm{~mL}$ columns (GE Healthcare) in an ÄKTA Pure system (GE Healthcare). Elution was achieved by a linear gradient of elution buffer $\left(20 \mathrm{mmol} \mathrm{L}^{-1}\right.$ Tris- $\mathrm{HCl}, 500 \mathrm{mmol} \mathrm{L}^{-1}$ $\mathrm{NaCl}, 500 \mathrm{mmol} \mathrm{L}^{-1}$ imidazole, $\mathrm{pH} 8$ ) and the recovered proteins were finally dialyzed against sodium bicarbonate with salt $\left(166 \mathrm{mmol} \mathrm{L}^{-1} \mathrm{NaHCO}_{3}, 333 \mathrm{mmol} \mathrm{L}^{-1} \mathrm{NaCl}\right.$, $\mathrm{pH}$ 8) buffer and centrifuged $(15 \mathrm{~min}, 15,000 \times \mathrm{g})$ to remove insoluble aggregates. In the case of GFP-H6, plain sodium bicarbonate without additional salt (166 mmol L $\mathrm{NaHCO}_{3}$, pH 8) buffer was used.

\section{Protein purity, integrity and concentration}

Protein purity was determined by sodium dodecyl sulfate polyacrylamide gel electrophoresis (SDS-PAGE) followed by Western blot (WB) immunodetection, using anti-His monoclonal antibody (Santa Cruz Biotechnology). On the other hand, protein integrity was evaluated by matrixassisted laser desorption ionization time-of-flight (MALDI-TOF) mass spectrometry. The final protein concentration prior experimental was determined by Bradford's assay.

\section{Electron microscopy}

Ultrastructural characterization of T22-GFP-H6, T22GFP-H6(LOOP), H6-GFP-T22 and GFP-H6 nanomorphometry (size and shape) was determined at nearly native state with field emission scanning electron microscopy (FESEM). Drops of $3 \mu \mathrm{L}$ of samples diluted at $0.3 \mathrm{mg} \mathrm{mL}^{-1}$ were directly deposited on silicon wafers (Ted Pella Inc.) for $30 \mathrm{~s}$, excess of liquid blotted, air dried, 

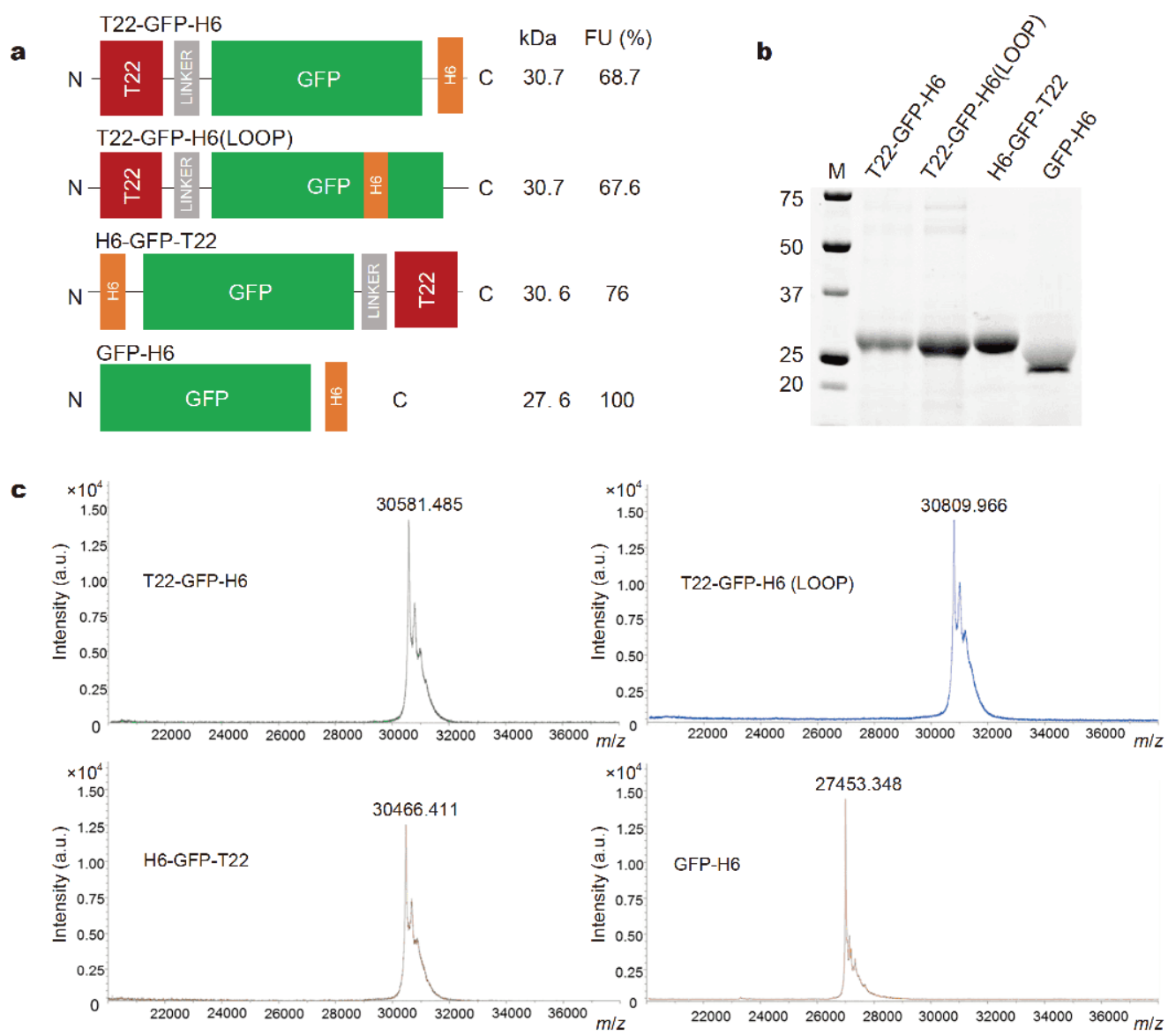

Figure 1 Properties of building blocks and protein nanoparticles. (a) Modular organization of the multifunctional proteins used in the study. Segment sizes are indicative. Protein names are according to the order of modules in the constructs. T22-GFP-H6(LOOP) refers to the insertion of H6 into a solvent-exposed permissive loop of GFP. Theoretical molecular masses are indicated in $\mathrm{kDa}$, as well as the specific fluorescence (FU) relative to GFP-H6. (b) Protein purity upon purification, shown by SDS-PAGE, demonstrating their proteolytic stability as single molecular mass species. M in the image indicates the molecular marker lane, showing the molecular masses in $\mathrm{kDa}$. (c) Mass spectrometry of the same protein samples.

and immediately observed without coating with a FESEM Zeiss Merlin (Zeiss) operating at $1 \mathrm{kV}$ and equipped with a high resolution in-lens secondary electron detector. Representative images of general fields and nanostructure details were captured at two high magnifications $(100,000 \times$ and $300,000 \times)$.

\section{In silico calculations}

UCSF Chimera software [39] was used for measuring the highest theoretical distances among amino acids in GFP monomers and dimers. With this purpose, 1GFL PDB structure was used, consisting in a dimeric structure solved by X-ray diffraction with a resolution of $1.9 \AA$ [40]. The measurements serve as an idea of the nature of GFPproteins building blocks based on their hydrodynamic size.

\section{Volume size distribution and fluorescence emission}

Volume size distribution of unassembled and assembled proteins was determined by dynamic light scattering (DLS), at $633 \mathrm{~nm}$ and $25^{\circ} \mathrm{C}$ in a Zetasizer Nano ZS (Malvern Instruments Limited), in a ZEN2112 $3 \mathrm{~mm}$ quartz cuvette. Measurements were done in triplicate for error estimation and peak values referred to the average mode of the populations. In order to prove their oligomeric nature, T22-GFP-H6 hydrodynamic size was measured after exposing the protein either to 3\% SDS or ethylenediaminetetraacetic acid (EDTA) at 1:1 molar ratio. Green fluorescence emission of proteins was determined at $510 \mathrm{~nm}$ using a Varian Cary eclipse fluorescence spectrophotometer (Agilent Technologies) upon excitation at $488 \mathrm{~nm}$. For that, all proteins were used at $1 \mathrm{mg} \mathrm{mL}^{-1}$ in a final volume of $100 \mu \mathrm{L}$. 


\section{Cell culture and protein internalization}

HeLa CXCR4 ${ }^{+}$cells were used to study the performance of the recombinant proteins in vitro. HeLa cells were maintained in Eagle minimum essential medium (MEM Alpha $1 \times$ GlutaMAX $^{\mathrm{TM}}$, Gibco) supplemented with $10 \%$ fetal bovine serum (Gibco) at $37^{\circ} \mathrm{C}$ in a $5 \% \mathrm{CO}_{2}$ humidified atmosphere. A preliminary MTT-luci assay was done to assess lack of protein toxicity. Essentially, a CellTiter-Glo ${ }^{\circledR}$ Luminiscent Cell Viability Assay (Promega Corporation) was performed after protein exposure at $1 \mu \mathrm{mol} \mathrm{L}{ }^{-1}$ and during $48 \mathrm{~h}$ as previously described [17]. To monitor protein internalization, HeLa cells were cultured on 24-well plates at $3 \times 10^{4}$ cells/well for $24 \mathrm{~h}$ until reaching $70 \%$ confluence. Proteins were incubated for 2 and $24 \mathrm{~h}$ at different concentrations $(25,100$ and $\left.1000 \mathrm{nmol} \mathrm{L}^{-1}\right)$ in presence of OptiPRO ${ }^{\mathrm{TM}}$ serum free medium (Gibco) supplemented with $L$-glutamine. Additionally, specific internalization through CXCR4 receptor was assessed by adding a specific antagonist, AMD3100 [41,42], which inhibits the specific interaction between T22 and CXCR4. This chemical compound was added at a final concentration of $10 \mu \mathrm{mol} \mathrm{L}^{-1}$ (10 times the highest protein concentration) for $1 \mathrm{~h}$ prior to protein incubation [43]. After protein exposure, cells were detached using $1 \mathrm{mg} \mathrm{mL}^{-1}$ Trypsin-EDTA (Gibco) for $15 \mathrm{~min}$ at $37^{\circ} \mathrm{C}$, a harsh protocol designed to remove externally attached protein [44]. Intracellular protein fluorescence was determined by flow cytometry using a fluorescence assisted cell sorting (FACS)-Canto system (Becton Dickinson) using a $15 \mathrm{~mW}$ air-cooled argon ion laser exciting at $488 \mathrm{~nm}$. Intracellular protein fluorescence was measured in duplicate for each condition.

\section{Confocal laser scanning microscopy}

For confocal microscopy, HeLa cells were grown on MatTek plates (MatTek Corporation) for $48 \mathrm{~h}$ (50,000 cells/well). Upon exposure to $1000 \mathrm{nmol} \mathrm{L}^{-1}$ of protein for $24 \mathrm{~h}$, cell nuclei were labelled with $5 \mu \mathrm{g} \mathrm{mL}^{-1}$ Hoechst 33342 (ThermoFisher), rendering a blue signal, and plasma membrane with $2.5 \mu \mathrm{g} \mathrm{mL}^{-1}$ CellMask $^{\mathrm{TM}}$ Deep Red (ThermoFisher), rendering a red signal, for $10 \mathrm{~min}$ at room temperature. Cells were then washed in phosphate buffer saline (PBS) buffer (Sigma-Aldrich). Images were collected on an inverted TCS SP5 Spectral confocal microscope (Leica Microsystems) using $63 \times(1.4$ NA) oil immersion objective lenses. Excitation was reached via a $405 \mathrm{~nm}$ blue diode laser for Hoechst 33342, $488 \mathrm{~nm}$ line of an argon ion laser for GFP and $633 \mathrm{~nm}$ line of a HeNe laser for CellMask ${ }^{\mathrm{TM}}$ Deep Red. Optimized emission detection bandwidths were configured to avoid inter-channel crosstalk and multitrack sequential acquisition settings were used. The confocal pinhole was set to 1 Airy unit and $z$-stacks acquisition intervals were chosen to satisfy Nyquist sampling criteria. Images were processed using Imaris v 7.2.1 software (Bitplane). Threedimensional (3D) images were processed using the Surpass Module.

\section{Data analysis}

Quantitative data are expressed as mean \pm standard error. Pairwise comparisons of conditions for each protein were made with Tukey's HSD Q-test. Significance was accepted at $p<0.05$. All statistical analyses were performed with PAST3.

\section{RESULTS}

To analyze the potential impact of alternative modular arrangements and the need of specific end-terminal placement of specific functional domains, we have designed, produced and purified the fusion protein H6-GFP-T22, for comparative functional and structural examination with T22-GFP-H6. For a deep analysis of the impact of modular distribution, we included the T22-lacking version GFP-H6 [45] (Fig. 1a), and T22-GFP-H6(LOOP), in which the hexahistidine tail was inserted into a solventexposed permissive loop of GFP [30] (Fig. 1a). As the other proteins, H6-GFP-T22 was efficiently produced in E. coli as a proteolytically stable, single protein species of expected molecular mass (Fig. 1b, c). Importantly, being highly fluorescent (Fig. 1a), this protein was suitable for tracking in further comparative experiments to study protein-cell interactions and internalization by flow cytometry and confocal microscopy. When determining the self-assembling properties of this new modular distribution we noted that, in contrast with the original T22GFP-H6 (assembling as $12 \mathrm{~nm}$-oligomers), H6-GFP-T22 was unable to self-assemble as regular nanoparticles under the conditions that trigger the nanoscale organization of T22-GFP-H6 (Fig. 2a-c). H6-GFP-T22 showed a hydrodynamic size $(5.6 \mathrm{~nm})$ compatible to the monomeric form of GFP (Fig. 2d). GFP-H6 and T22-GFP-H6(LOOP) showed a slightly larger average particle size $(6.5 \mathrm{~nm})$, compatible to an unbalanced mixture between monomeric $(5.4 \mathrm{~nm})$ and dimeric forms (around $7.7 \mathrm{~nm}$ ) of GFP (Fig. 2d). Both the presumed dimeric forms and the multimeric (decameric [24]) T22-GFP-H6, were disassembled to the smaller $5.6 \mathrm{~nm}$ building blocks (Fig. 2c) by either the addition of EDTA, which removed the cross-molecular interacting divalent cations supportive of nanoparticle formation [30], or by the addition of the 
$\mathbf{a}$
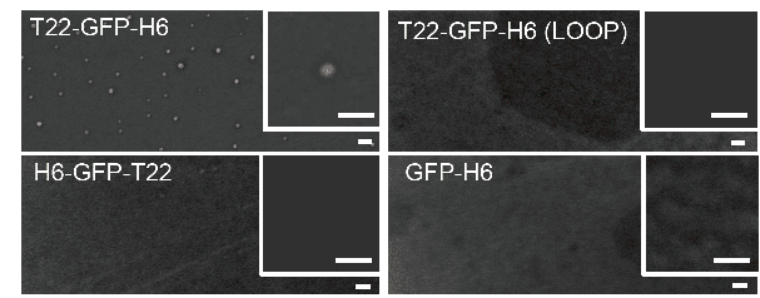

b

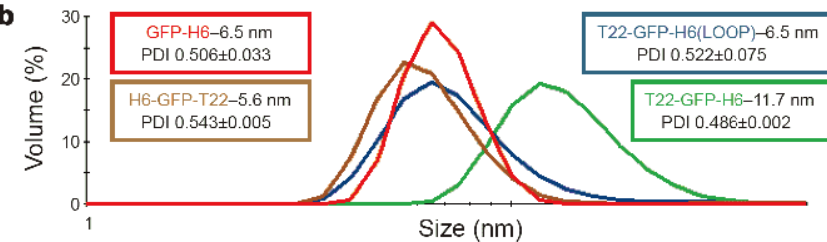

C

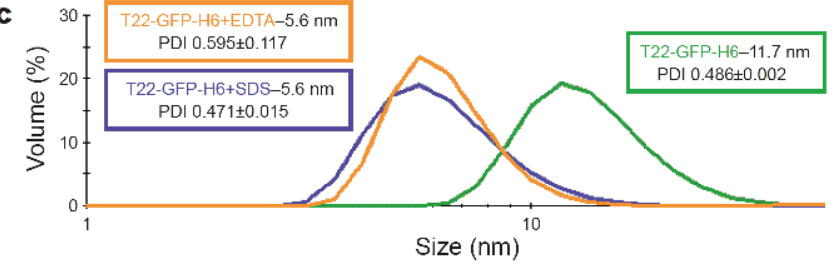

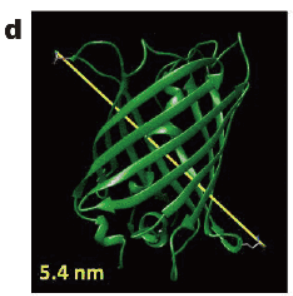
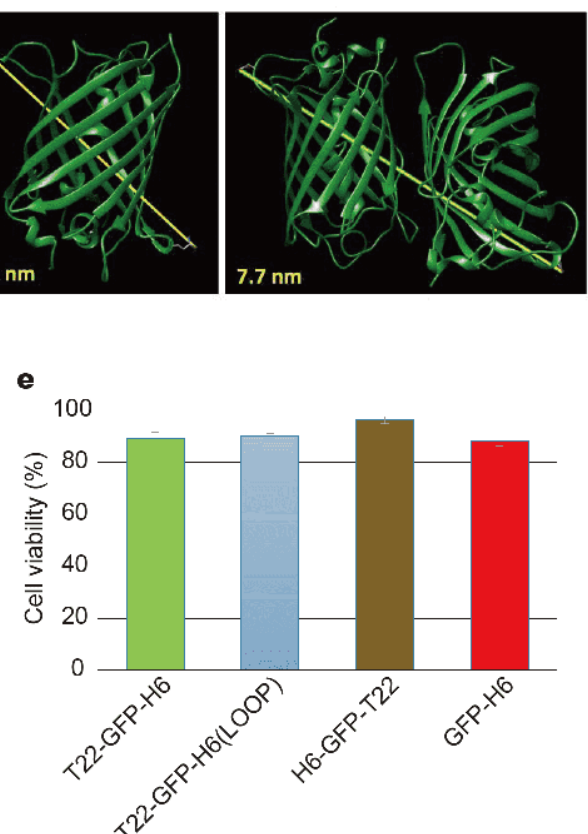

Figure 2 Protein assembly as oligomeric nanoparticles. (a) Representative FESEM images of the GFP-based recombinant proteins upon purification. Bars indicate $30 \mathrm{~nm}$. (b) Hydrodynamic size of unassembled proteins and protein nanoparticles, indicating the peak size of DLS plots and the polydispersion index (PDI). (c) Controlled disassembly of T22-GFP-H6 nanoparticles mediated by 3\% SDS or by EDTA at 1:1 molar ratio related to His residues. (d) Molecular modelling of native GFP showing both the monomeric and dimeric forms and their larger atomic distances. (e) MTT cell viability analysis of HeLa cells exposed to pure proteins (at $1000 \mathrm{nmol} \mathrm{L}^{-1}$ ) for $48 \mathrm{~h}$. Data are referred to the viability of non-exposed cells cultured under the same conditions.

denaturing agent SDS. None of these proteins showed toxicity when exposed to cultured CXCR $4^{+} \mathrm{HeLa}$ cells (Fig. 2e).

Irrespective of its oligomerization status, we were interested in knowing whether T22, in a C-terminal accommodation, would be able to recognize its CXCR4 receptor and promote internalization into $\mathrm{CXCR} 4^{+}$cells. The intrinsic fluorescence of H6-GFP-T22 allowed an easy tracking of the protein in protein-exposed cells. As observed (Fig. 3a), H6-GFP-T22 was only moderately able to penetrate $\mathrm{CXCR} 4^{+} \mathrm{HeLa}$ cells in culture in a timedependent fashion, with respect to the control T22-GFPH6. Then, it was observed about 5-fold less intracellular fluorescence (corrected by the specific fluorescence, and therefore, representative of protein amounts) than T22GFP-H6, and 4-fold less when compared with T22-GFPH6(LOOP). This profile, similar to data recorded at both 2 and 24 h (Fig. 3a), was indicative of a less efficient cell uptake of the protein mediated by the T22 peptide when positioned at the $\mathrm{C}$ terminus of the protein. This fact could be not straightforward accounted by the lack of assembly into nanoparticles, as T22-GFP-H6(LOOP) was also unable to form regular oligomers (Fig. 2) and it showed a cell penetrability potential only slightly lower than that of the parental protein (Fig. 3a). The similar uptake of T22-GFP-H6 and T22-GFP-H6(LOOP) indicates that the position of $\mathrm{H} 6$, the protein segment responsible for oligomerization, has only a minor effect on the cell penetrability mediated by the N-terminal T22. This fact can be explained as an indirect effect because the regular multivalent presentation of the CXCR4 ligand (promoted by functional H6) favors cooperative cell binding and endosome formation in a virus-like fashion [46]. When checking whether the residual binding of H6GFP-T22 to HeLa cells was CXCR4-dependent, we noted that the specificity of T22-mediated interaction was also lost. At $1 \mu \mathrm{mol} \mathrm{L}^{-1}$ protein concentration, the CXCR4 antagonist AMD3100 [41,42] blocked the penetration of T22-GFP-H6 by about 75\%, while the uptake of H6-GFPT22 was only reduced by $15 \%$ (Fig. $3 \mathrm{~b}$ ). At low protein doses, the specificity of the internalization process generically increased but it was still non-significant and lower in the case of H6-GFP-T22 than when testing the parental construct (79\% versus 98\%). This indicated that the residual internalization of H6-GFP-T22 was mostly CXCR4-independent.

Envisaging that this fact might also affect the intracellular localization of the protein, we analyzed 

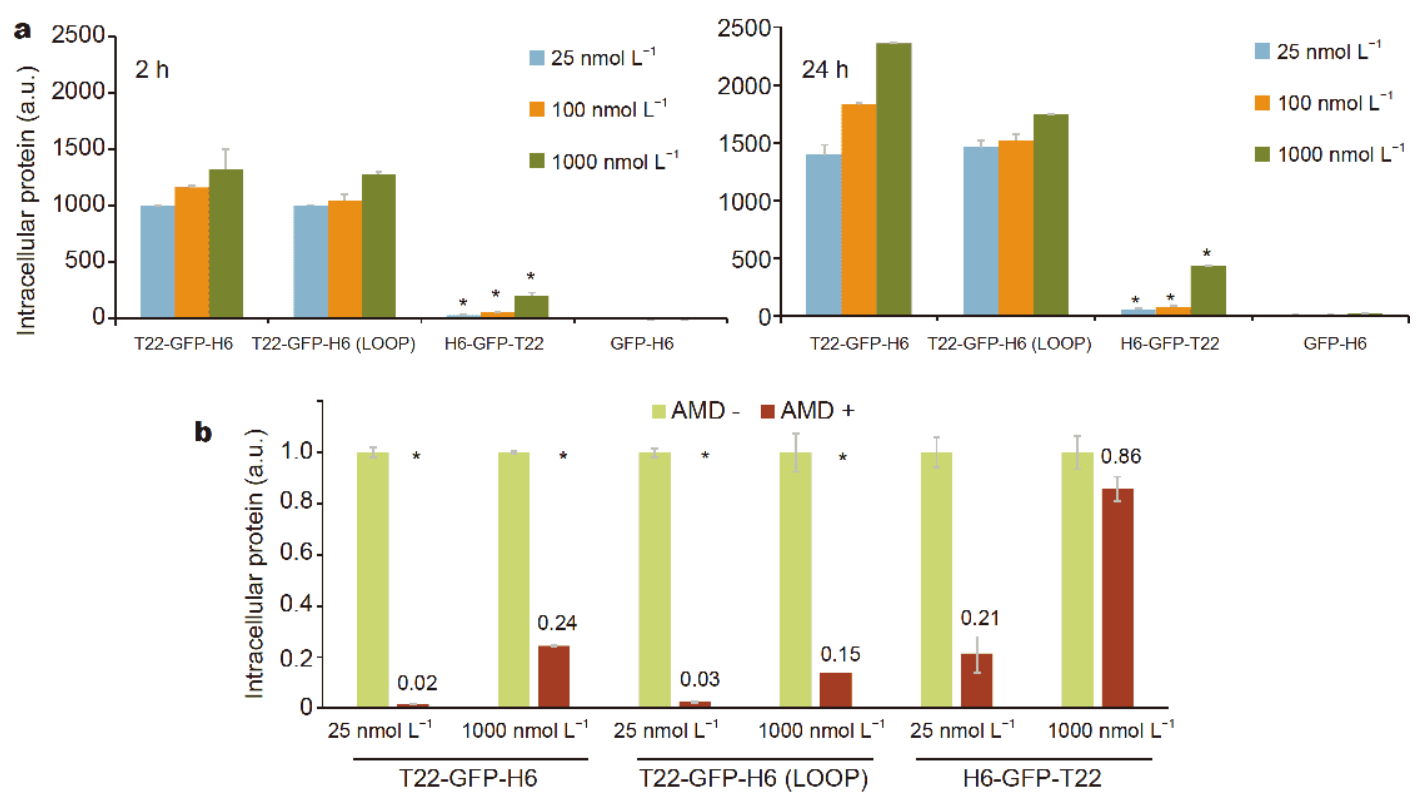

Figure 3 Efficacy and specificity of cell penetrability of protein nanoparticles. (a) Internalization of T22-GFP-H6, T22-GFP-H6(LOOP), H6-GFP-T22 and GFP-H6 in CXCR4 ${ }^{+}$HeLa cells, recorded after 2 and $24 \mathrm{~h}$ of exposure, at three different concentrations $\left(25,100\right.$ and $\left.1000 \mathrm{nmol} \mathrm{L}{ }^{-1}\right)$. Crude fluorescence values were normalized by the specific fluorescence emission of each protein to allow molar-based comparison. $Y$-axis in arbitrary units of fluorescence (a.u.). Significant differences with T22-GFP-H6 internalization under the same conditions (included as a control) are represented by * $(p<0.001)$. (b) Relative intracellular fluorescence values (a.u.) for each protein under prior treatment of CXCR4 ${ }^{+}$HeLa cells with AMD3100, a specific inhibitor of T22-CXCR4 binding, compared with those obtained under the same conditions in absence of this compound. The analysis was done $2 \mathrm{~h}$ after exposure. Significant difference with protein internalization under the same conditions but without AMD3100 are represented by ${ }^{*}(p<0.001)$. The standard error is represented by grey lines at each sample.

protein-exposed HeLa cells by confocal microscopy. Indeed, while T22-GFP-H6 and T22-GFP-H6(LOOP) distributed as a perinuclear punctuated pattern, indicative of an endosomal penetration route, H6-GFP-T22 fluorescence mostly accumulated at the cell membrane level, with a very modest true internalization (Fig. 4, top). Control GFP-H6 was not detected in cells. These patterns were fully confirmed by 3D cell imaging, which again supported the strong membrane association of H6-GFPT22 (Fig. 4 bottom and Fig. 5) with only limited internalization, in contrast to what happened to the proteins with the amino terminal T22. Since previous to flow cytometric analysis, protein-exposed cells were submitted to a harsh trypsin treatment to remove the externally attached protein [44], the detected green fluorescence (in particular the yellow merging) revealed a very tight in-
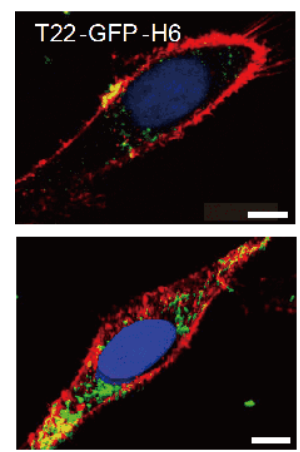
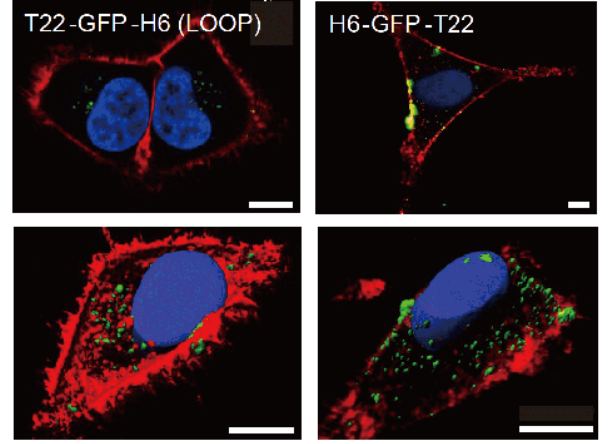
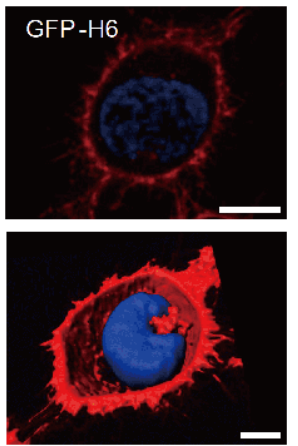

Figure 4 Intracellular localization of proteins in protein-exposed cells. 2D confocal imaging of protein-exposed HeLa cells. Red signal indicates labelled membranes, blue signal labelled nuclear nucleic acids and the green signal is the natural green fluorescence of proteins. Cells cultured in absence of proteins are also shown for a clear visualization of blue and red signals in absence of protein. At the bottom, 3D Imaris reconstruction of confocal stacks along the $z$ axis of the same experiments. Analysis was performed after $24 \mathrm{~h}$ of protein exposure at $1 \mu \mathrm{mol} \mathrm{L}{ }^{-1}$. Bars indicate $10 \mu \mathrm{m}$. 

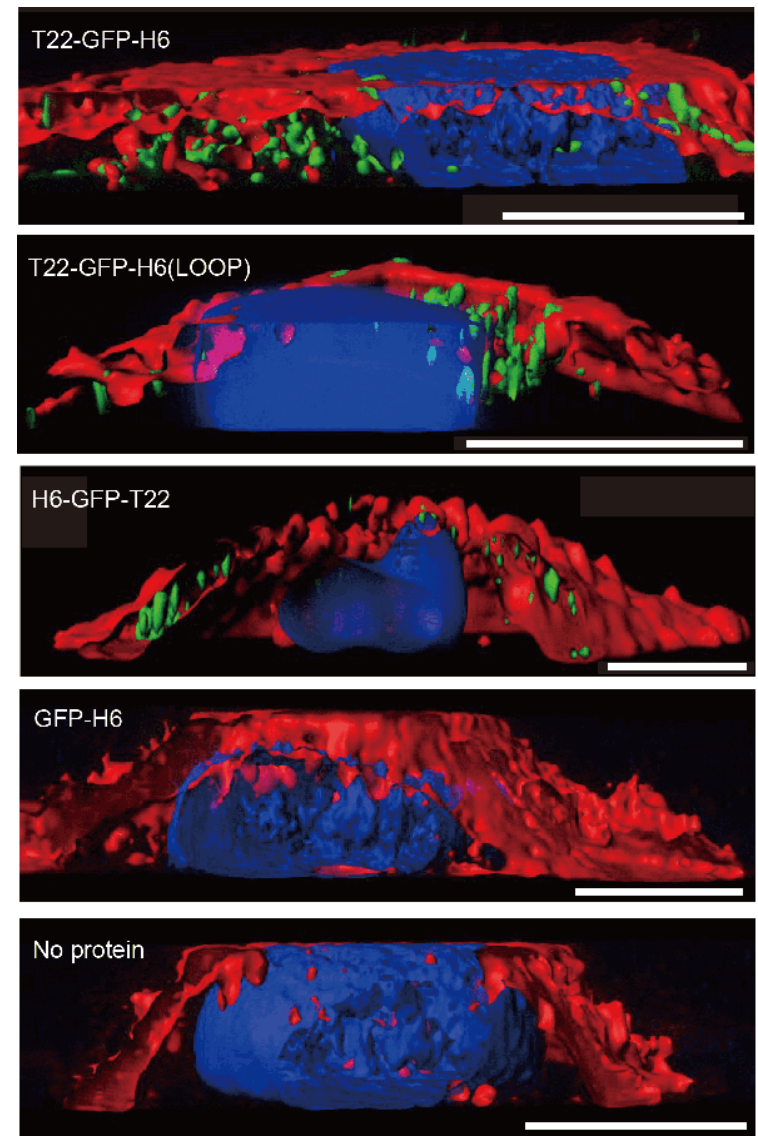

Figure 5 Intracellular and membrane localization of proteins in protein-exposed cells. Fine details of 3D Imaris reconstructions of confocal stacks along the $z$ axis, showing the green fluorescent material. Cells cultured in absence of proteins are also shown. Red signal indicates labelled membranes and blue signal labelled nuclear nucleic acids. The analysis was performed after $24 \mathrm{~h}$ of protein exposure at $1 \mu \mathrm{mol} \mathrm{L}^{-1}$. Bars indicate $10 \mu \mathrm{m}$.

teraction between the protein and cell membranes. Such interaction appeared as different from that promoting endosomal internalization (assumed to be CXCR4-dependent and responsible for the recorded mild specificity), and an important fraction of H6-GFP-T22 was neither bound nor internalized.

\section{DISCUSSION}

Altogether, the set of data presented here firmly demonstrate the relevance of domain accommodation in modular proteins, regarding both the property to form supramolecular protein materials through self-assembling but also the functionality of individual functional modules. The combination of a cationic domain plus a histidine-rich region, surrounding a core scaffold protein, was revealed as a transversal protein engineering platform to construct functional protein-only nanoparticles for clinical applications [25]. In this context, this architectonic principle at the nanoscale has been adapted to develop antimicrobial nanoparticles [47], blood-brain-barrier crossing agents [48], CD44-targeted nanoparticles [49], tumor imaging agents [24], vehicles for tumor-targeted chemical drug delivery [23], theranostic agents [18] and protein-only, highly cytotoxic antitumoral drugs effective in colorectal cancer [38] and in acute myeloid leukemia [15]. The symmetry associated to the protein-assembling process, for which both a cationic peptide and a polyhistidine tail are required [25], is lost when the histidinerich segment is placed in the alternative N-terminal position or in an intermediate localization, in an overhanging loop of GFP (Fig. 2b). Also, irrespective of the formation of nanoparticles from protein building blocks, $\mathrm{T} 22$, strongly cationic, is fully functional at the $\mathrm{N}$ terminus but not in the $\mathrm{C}$ terminus (Fig. 3), where this peptide is not able to specifically and effectively promote protein internalization through the cell surface receptor CXCR4. At high concentrations (Fig. 3b), T22 seems to act as still inefficient cell-penetrating cationic peptide, with untargeted cell penetrability [50]. The higher penetrability of T22-GFP-H6 compared with that of T22GFP-H6(LOOP) (Figs 3-5) can be accounted by the multivalent attachment of the first construct, which is expected to favor cooperativity in both binding and endosomal mediated internalization, compared with that of monomers and dimers formed by T22-GFP-H6(LOOP) [46]. Finally, a free amino terminus of T22 is the requirement for a proper association with CXCR4. This might be related to the fact that the $\mathrm{N}$-terminal repeat Tyr-Arg-Lys in T22 is highly associated with the antiviral activity of the peptide, which is based on the blockage of HIV binding to CXCR4 [51]. A failure in T22-CXCR4 interaction by a wrong positioning of T22 in the fusion protein aborts the selectivity of the ligand by its cellular receptor and conduces to an unspecific and inefficient binding to cells, which precludes endosomal internalization (Figs 3-5). As CXCR4 is not only a relevant and transversal tumoral marker but a key receptor in HIV infection, and T22 is a useful antagonist in the infection process [26-28], reaching a rationale for a proper T22 positioning in potential antiviral drugs is of wider interest in the development of antitumoral drugs and therapeutic strategies.

\section{CONCLUSIONS}

We have determined here that the peptide $\mathrm{H} 6$ is a potent architectonic tag that allows the controlled oligomeriza- 
tion of recombinant fusion proteins. Moreover, this segment is only active when displaying a free carboxy terminus, but not when displaying the amino terminus or in absence of free termini. Besides this, the potent ligand of CXCR4, the peptide T22, promotes efficient $\mathrm{CXCR} 4^{+}$cell binding and internalization through its free amino terminal end. Although the nanoscale oligomerization supported by a properly accommodated $\mathrm{H} 6$ clearly favors CXCR4-dependent cell internalization, the requirement of a free amino terminal end of T22 is irrespective of the protein oligomerization as regular nanoparticles. Sustained by the growing interest in protein-only smart materials with clinical applicability, these findings offer relevant clues for the development of transversal and simple platforms based on modular protein engineering and biological fabrication.

Received 24 July 2019; accepted 11 August 2019; published online 19 September 2019

1 Casanova I, Unzueta U, Arroyo-Solera I, et al. Protein-driven nanomedicines in oncotherapy. Curr Opin Pharmacol, 2019, 47: 17

2 Loo Y, Goktas M, Tekinay AB, et al. Self-assembled proteins and peptides as scaffolds for tissue regeneration. Adv Healthcare Mater, 2015, 4: 2557-2586

3 Kumar VA, Wang BK, Kanahara SM. Rational design of fiber forming supramolecular structures. Exp Biol Med, 2016, 241: 899908

4 Yeates TO, Liu Y, Laniado J. The design of symmetric protein nanomaterials comes of age in theory and practice. Curr Opin Struct Biol, 2016, 39: 134-143

5 Sutherland TD, Rapson TD, Huson MG, et al. Recombinant structural proteins and their use in future materials. In: Parry D, Squire J, Eds. Fibrous Proteins: Structures and Mechanisms. Subcellular Biochemistry, Vol 82. Cham: Springer, 2017. 491-526

6 Guttenplan APM, Young LJ, Matak-Vinkovic D, et al. Nanoscale click-reactive scaffolds from peptide self-assembly. J Nanobiotechnol, 2017, 15: 70

7 Wei G, Su Z, Reynolds NP, et al. Self-assembling peptide and protein amyloids: from structure to tailored function in nanotechnology. Chem Soc Rev, 2017, 46: 4661-4708

8 Yeates TO. Geometric principles for designing highly symmetric self-assembling protein nanomaterials. Annu Rev Biophys, 2017, 46: $23-42$

9 DiMarco RL, Heilshorn SC. Multifunctional materials through modular protein engineering. Adv Mater, 2012, 24: 3923-3940

10 Sanchez-Garcia L, Martín L, Mangues R, et al. Recombinant pharmaceuticals from microbial cells: a 2015 update. Microb Cell Fact, 2016, 15: 33

11 Arís A, Villaverde A. Modular protein engineering for non-viral gene therapy. Trends Biotechnol, 2004, 22: 371-377

12 Vázquez E, Ferrer-Miralles N, Mangues R, et al. Modular protein engineering in emerging cancer therapies. Curr Phar Des, 2009, 15: 893-916

13 Serna N, Sánchez-García L, Unzueta U, et al. Protein-based therapeutic killing for cancer therapies. Trends Biotechnol, 2018, 36:
318-335

14 Díaz R, Sánchez-García L, Serna N, et al. Engineering a recombinant chlorotoxin as cell-targeted cytotoxic nanoparticles. Sci China Mater, 2019, 62: 892-898

15 Díaz R, Pallarès V, Cano-Garrido O, et al. Selective CXCR4 ${ }^{+}$cancer cell targeting and potent antineoplastic effect by a nanostructured version of recombinant ricin. Small, 2018, 14: e1800665

16 Sánchez-García L, Serna N, Mattanovich M, et al. The fusogenic peptide HA2 impairs selectivity of CXCR4-targeted protein nanoparticles. Chem Commun, 2017, 53: 4565-4568

17 Serna N, Sánchez JM, Unzueta U, et al. Recruiting potent membrane penetrability in tumor cell-targeted protein-only nanoparticles. Nanotechnology, 2019, 30: 115101

18 Serna N, Céspedes MV, Sánchez-García L, et al. Peptide-based nanostructured materials with intrinsic proapoptotic activities in CXCR4 $^{+}$solid tumors. Adv Funct Mater, 2017, 27: 1700919

19 Grove TZ, Osuji CO, Forster JD, et al. Stimuli-responsive smart gels realized via modular protein design. J Am Chem Soc, 2010, 132: 14024-14026

20 Howorka S. Rationally engineering natural protein assemblies in nanobiotechnology. Curr Opin Biotech, 2011, 22: 485-491

21 Cai L, Heilshorn SC. Designing ECM-mimetic materials using protein engineering. Acta Biomater, 2014, 10: 1751-1760

22 Binz HK, Amstutz P, Plückthun A. Engineering novel binding proteins from nonimmunoglobulin domains. Nat Biotechnol, 2005, 23: $1257-1268$

23 Céspedes MV, Unzueta U, Aviñó A, et al. Selective depletion of metastatic stem cells as therapy for human colorectal cancer. EMBO Mol Med, 2018, 10: e8772

24 Rueda F, Céspedes MV, Conchillo-Solé O, et al. Bottom-up instructive quality control in the biofabrication of smart protein materials. Adv Mater, 2015, 27: 7816-7822

25 Unzueta U, Ferrer-Miralles N, Cedano J, et al. Non-amyloidogenic peptide tags for the regulatable self-assembling of protein-only nanoparticles. Biomaterials, 2012, 33: 8714-8722

26 Nakashima H, Masuda M, Murakami T, et al. Anti-human immunodeficiency virus activity of a novel synthetic peptide, T22 ([Tyr-5,12, Lys-7]polyphemusin II): a possible inhibitor of viruscell fusion. Antimicrobial Agents ChemoTher, 1992, 36: 1249-1255

27 Tamamura H, Kuroda M, Masuda M, et al. A comparative study of the solution structures of tachyplesin I and a novel anti-HIV synthetic peptide, T22 ([Tyr5,12, Lys7]-polyphemusin II), determined by nuclear magnetic resonance. Biochim Biophys Acta-Protein Struct Mol Enzymol, 1993, 1163: 209-216

28 Tamamura H, Arakaki R, Funakoshi $\mathrm{H}$, et al. Effective lowly cytotoxic analogs of an HIV-cell fusion inhibitor, T22 ([Tyr5,12, Lys7]-polyphemusin II). Bioorg Med Chem, 1998, 6: 231-238

29 Unzueta U, Céspedes MV, Ferrer-Miralles N, et al. Intracellular $\mathrm{CXCR}^{+}$cell targeting with T22-empowered protein-only nanoparticles. Int J Nanomed, 2012, 4533-4544

30 López-Laguna $\mathrm{H}$, Unzueta U, Conchillo-Solé $\mathrm{O}$, et al. Assembly of histidine-rich protein materials controlled through divalent cations. Acta Biomater, 2019, 83: 257-264

31 Vazquez E, Roldán M, Diez-Gil C, et al. Protein nanodisk assembling and intracellular trafficking powered by an arginine-rich (R9) peptide. Nanomedicine, 2010, 5: 259-268

32 Balkwill F. The significance of cancer cell expression of the chemokine receptor CXCR4. Semin Cancer Biol, 2004, 14: 171-179

33 Kim J, Takeuchi H, Lam ST, et al. Chemokine receptor CXCR4 expression in colorectal cancer patients increases the risk for re- 
currence and for poor survival. J Clin Oncol, 2005, 23: 2744-2753

34 Burger JA, Kipps TJ. CXCR4: a key receptor in the crosstalk between tumor cells and their microenvironment. Blood, 2006, 107: $1761-1767$

35 Kim J, Mori T, Chen SL, et al. Chemokine receptor CXCR4 expression in patients with melanoma and colorectal cancer liver metastases and the association with disease outcome. Ann Surg, 2006, 244: 113-120

36 Hermann PC, Huber SL, Herrler T, et al. Distinct populations of cancer stem cells determine tumor growth and metastatic activity in human pancreatic cancer. Cell Stem Cell, 2007, 1: 313-323

37 Croker AK, Allan AL. Cancer stem cells: implications for the progression and treatment of metastatic disease. J Cell Mol Med, 2008, 12: $374-390$

38 Sánchez-García L, Serna N, Álamo P, et al. Self-assembling toxinbased nanoparticles as self-delivered antitumoral drugs. J Control Release, 2018, 274: 81-92

39 Pettersen EF, Goddard TD, Huang CC, et al. UCSF chimera? A visualization system for exploratory research and analysis. J Comput Chem, 2004, 25: 1605-1612

40 Yang F, Moss LG, Phillips GN. The molecular structure of green fluorescent protein. Nat Biotechnol, 1996, 14: 1246-1251

41 Kim J, Connelly KL, Unterwald EM, et al. Chemokines and cocaine: CXCR4 receptor antagonist AMD3100 attenuates cocaine place preference and locomotor stimulation in rats. Brain Behav Immun, 2017, 62: 30-34

42 Jung YH, Lee DY, Cha W, et al. Antitumor effect of CXCR4 antagonist AMD3100 on the tumorigenic cell line of BHP10-3 papillary thyroid cancer cells. Head Neck, 2016, 38: 1479-1486

43 Kim HY, Hwang JY, Kim SW, et al. The CXCR4 antagonist AMD3100 has dual effects on survival and proliferation of myeloma cells in vitro. Cancer Res Treat, 2010, 42: 225

44 Richard JP, Melikov K, Vives E, et al. Cell-penetrating peptides. J Biol Chem, 2003, 278: 585-590

45 Céspedes MV, Unzueta U, Tatkiewicz $\mathrm{W}$, et al. In vivo architectonic stability of fully de Novo designed protein-only nanoparticles. ACS Nano, 2014, 8: 4166-4176

46 Unzueta U, Céspedes MV, Vázquez E, et al. Towards protein-based viral mimetics for cancer therapies. Trends Biotechnol, 2015, 33: 253-258

47 Serna N, Sánchez-García L, Sánchez-Chardi A, et al. Protein-only, antimicrobial peptide-containing recombinant nanoparticles with inherent built-in antibacterial activity. Acta Biomater, 2017, 60: 256-263

48 Serna N, Céspedes MV, Saccardo P, et al. Rational engineering of single-chain polypeptides into protein-only, BBB-targeted nanoparticles. Nanomed-Nanotechnol Biol Med, 2016, 12: 1241-1251

49 Pesarrodona M, Ferrer-Miralles N, Unzueta U, et al. Intracellular targeting of $\mathrm{CD} 44^{+}$cells with self-assembling, protein only nanoparticles. Int J Pharm, 2014, 473: 286-295

50 Guo Z, Peng H, Kang J, et al. Cell-penetrating peptides: possible transduction mechanisms and therapeutic applications. Biomed Rep, 2016, 4: 528-534

51 Tamamura H, Imai M, Ishihara T, et al. Pharmacophore identification of a chemokine receptor (CXCR4) antagonist, T22 ([Tyr 5,12, Lys 7]-polyphemusin II), which specifically blocks T cell-linetropic HIV-1 infection. Bioorg Med Chem, 1998, 6: 1033-1041

Acknowledgements We are indebted to Agencia Estatal de Investigación and to Fondo Europeo de Desarrollo Regional (grant BIO2016-76063-R, AEI/FEDER, UE) to Villaverde A, AGAUR (2017SGR-229) to Villaverde A and 2017SGR-865 GRC to Mangues R; CIBER-BBN (project NANOPROTHER) granted to Villaverde A and CIBER-BBN project 4 NanoMets to Mangues R; ISCIII (PI15/00272 cofounding FEDER) to Vázquez E and ISCIII (Co-founding FEDER) PIE15//00028 and PI18/00650 to Mangues R, and to EU COST Action CA 17140. We are also indebted to the Networking Research Center on Bioengineering, Biomaterials and Nanomedicine (CIBER-BBN) that is an initiative funded by the VI National R\&D\&I Plan 2008-2011, Iniciativa Ingenio 2010, Consolider Program, CIBER Actions and financed by the Instituto de Salud Carlos III, with assistance from the European Regional Development Fund. Protein production has been partially performed by the ICTS "NANBIOSIS", more specifically by the Protein Production Platform of CIBER in Bioengineering, Biomaterials \& Nanomedicine (CIBER-BBN)/IBB, at the UAB sePBioEs scientific-technical service (http://www.nanbiosis.es/portfolio/ul-protein-production-platform-ppp/) and the nanoparticle size analysis by the Biomaterial Processing and Nanostructuring Unit. Confocal and electron microscopy studies were performed at the Servei de Microscòpia and cell culture experiments at the SCAC, both located at the UAB. Molecular graphics and analyses were performed with UCSF Chimera, developed by the Resource for Biocomputing, Visualization, and Informatics at the University of California, San Francisco, with support from NIH P41GM103311. Villaverde A received an ICREA ACADEMIA award. Sánchez-García $\mathrm{L}$ and López-Laguna $\mathrm{H}$ were supported by a predoctoral fellowship from AGAUR (2018FI_B2_00051 and 2019FI_B_00352) respectively and Unzueta U by PERIS program from the Health Department of la Generalitat de Catalunya.

Author contributions Voltà-Durán E performed most of the experiments and figures, assisted by Cano-Garrido O, Serna N, LópezLaguna $\mathrm{H}$ and Sánchez-García L. Pesarrodona $\mathrm{P}$ designed and produced one of the proteins used here. Sánchez-Chardi A performed the electron microscopy and some statistics. Unzueta $U$ supervised the study. Mangues R, Villaverde A and Vázquez E conceived the whole study, which was mostly written by Villaverde A. All authors gave approval to the final version of the manuscript.

Conflict of interest Mangues R, Vázquez E and Villaverde A are cofounders of Nanoligent SL, a company devoted to the design of anticancer drugs based on T22. 


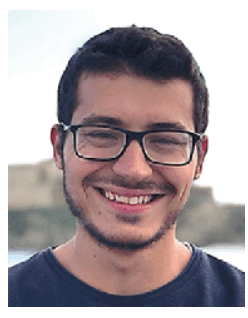

Eric Voltà-Durán graduated in biotechnology in 2018 and developed his Master thesis in Advanced Nanoscience and Nanotechnology at the Nanobiotechnology group led by Prof. Villaverde at the Autonomous University of Barcelona. $\mathrm{He}$ is currently starting a $\mathrm{PhD}$ in biotechnology in the same group, working on the design and production of proteins with biomedical interest. At present, he is focused on the rational engineering of CXCR4-targeted protein nanoparticles, with great potential in cancer therapy.

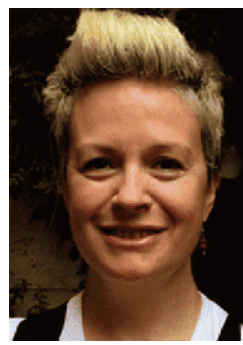

Esther Vázquez is a Senior Researcher at the Institut de Biotecnologia i de Biomedicina, Universitat Autònoma de Barcelona, Spain, and Associate Professor at the Department de Genètica i de Microbiologia of the same university. She is also member of the CIBER of Bioengineering, Biomaterials and Nanomedicine. Being formed at the State University of New York, USA, and after working in different universities on molecular medicine, she is now interested in protein drug design, recombinant protein production, nanobiotechnology and protein nanoparticles for targeted therapies.

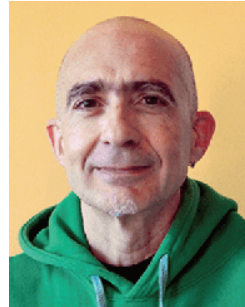

Antonio Villaverde graduated in biological sciences in 1982 and got his $\mathrm{PhD}$ in 1985. He has been scientifically formed in Barcelona, Madrid, London, Lausanne and Braunschweig. Since 1987, he has been a professor of microbiology at the Universitat Autònoma de Barcelona, Spain, where he got a Full Professorship in 2002. He leads the Nanobiotechnology group in this university and in the CIBER-BBN, focusing on the design of protein-based materials for biomedical applications. He founded the journal Microbial Cell Factories in 2002, being its Editor-in-Chief for 15 years. 